whole, give higher values for the resistances than those taken when it was small.

Accordingly, the results were grouped according to the breadth of the black film, and it was found that the mean value of the resistance of a ring $1 \mathrm{~mm}$. broad, deduced from experiments made when the breadth of the black was between

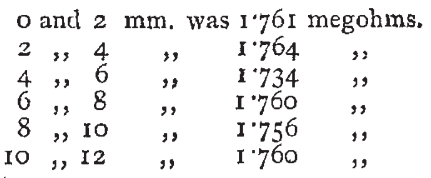

These numbers prove that the thickness of the black ring is independent of its breadith.

It was, however, thought possible that the thickness of the black film might be affected by that of the coloured portion of the film which appeared to be in contact with it, and accordingly the restilts were once more grouped with reference to that colour only.

The mean value of the resistances when the colour next to the black was the

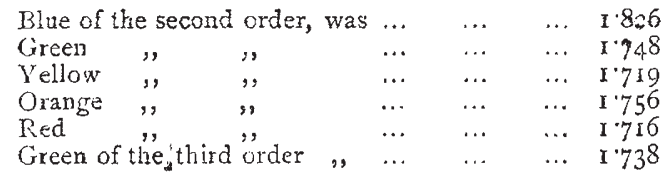

The first of these numbers 'is considerably larger than the rest, but it is deduced in great part from a high set of measurements which were obtained during the observations on the first cylinder. Equally high values were, however, obtained later on the same day when the colour next to the black was the crange of the second order, and on the only other occasion on which an observation was taken with the blue of the second order in contact with the black, the number obtained was 1 'j6o. Herce the high value, $r .826$, does not seem to have any special significance, and we conclude that the thickness of the black is independent of the portion of the film which appears to the naked eye to be in immediate contact with it.

The principal error with which these experiments are probably affected is due to the fact that the lower boundary of the black part of a film was not always strictly horizontal. When this was noticed to be the case, the breadth of the black ring was measured in several parts, and a mean value was deduced, but it was difficult for the observer to determine whether or no the further edge of the black was below that nearer to him. In spite, however, of this and the other possible errors of experiment, the numbers obtained certainly prove that the thickness of a biack film is uniform, and is very approximately constant under such variations of circumstance as those to which the films observed were exposed. One other point may be worthy of notice. The mean value of the resistance of a black ring $1 \mathrm{~mm}$. broad deduced from all the experiments was 1,750,000 ohms, and by applying Ohm's law to this we obtain for the thickness of the black film twelve-millionths of a millimetre. This value, which must be received with the cautions given above, is only one-third of that at which a film of the solution used would begin to appear black, and would make the thickness of the film one-forty-ninth part of the wave-length of $D$.

As Prof. Reinold and the writer are at present engaged in investigating the question of the magnitude of the radius of molecular attraction, a consideration of the various speculations as to molecular magnitudes, to which these experiments lead must be for the present postponed.

A. W. RÜCKER

\section{RAINFALL IN SOUTH INDIA}

THE probability of another failure of rain and consequent famine in South India gives to any facts connected with rainfall in that country so great an interest that I will not delay longer the publication of a result obtained by me several months ago in a paper which would have been presented to the Royal Society last session, but for the desire to complete it with some details expected by me from India.

Whether the amount of rain follows the decennial law or not, all the known causes of variation will pass, it may be believed, through all their phases within ten years; so that the yearly mean rainfall deduced fiom ten years' observations should give a considerable approximation to the mean from any series however long. Any deviations from this result would be expected to be small and irregular. The fact is otherwise, if the observations at Trevandrum, on the wrest coast, and at Madras on the east coast, may be taken (as has been done) for approximate representations of the variations for the country around.

The Trevandrum series of observations includes the years 1838 to 1876 . Taking the sums of rainfall for each ten years ( $1838-47,1839-48$, and so on), it appears that the amount was a maximum in the ten years $1843-52$, and equal to $76 \mathrm{r}$ inches, from which time it has gradually diminished (with occasional slight increases) till now, I $867-76$, when it is only 562 inches; or the yearty mean rainfall during the last ten years was nearly 20 inches less than a quarter of a century ago.

When we examine the Madras observations we find a quite similar result. The Madras series includes the period 1813 to 1876 : the ten-yearly sum of rain was a maximum in $1818-27$, and equal to 555 inches; it diminished to a minimum in $1828-37$, and equal to $38 \mathrm{z}$ inches; increased, as at Trevandrum, to a maximum in $1843-52$, and equal to 583 inches; diminishing thence to 396 inches in $1860-69$. The agreement with Trevandrum is complete till this period; but the sum increased at Madras to 510 inches in $1865-74$, diminished thence till now, whereas at Trevandrum the diminution has continued to the present time.

If we compare the diminutions at the two stations while they agreed, we find--

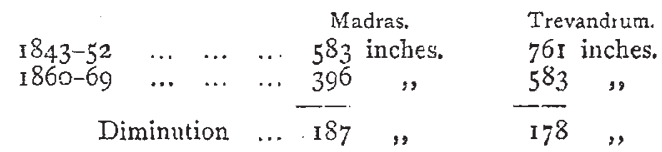

Or at both stations a diminution of the yearly mean rainfall of about I 8 inches. It will be of importance to ascertain whether this diminution has been experienced at more northern stations.

The yearly rainfall on the west coast of India, near Cape Comorin, was about 26 inches in I 844 ; it increased to about 70 inches at Trevandrum, thence to about 120 inches at Cananore, diminishing at Bombay and farther north, the maximum fall occurring somewhere between Cochin and Bombay. This variation does not depend wholly at least on the nearness of the stations to the range of the Ghats. It appears that the great atmospheric current sweeping over the Indian Ocean charged with vapour during the monsoons has a central current of maximum vapour depth or of velocity. If we can imagine that this central current shifts on the whole northwards from year to year for some time, the stations to the south will receive less and less rain, while those to the north will receive more; the total precipitation might thus remain the same. If we could suppose such a movement of the vapour masses to obey a law like that of the sunspots (and something resembling this has been found by me in the investigations for the isobaric lines and windcurrents in the British Isles), then we should find in such 
a case the same physical cause producing a maximum of rainfall at a northern station, at the same time as a minimum at a southern station. This is merely a suggestion to show the caution which may be necessary before we accept without qualification any fixed rule as to the similar actions of the same physical cause at Madras, Calcutta, and Bombay.

It may be asked to what extent the Trevandrum series of observations confirms the results given in NisURE (vol. xvi. p. 252) for Madras and Bombay, relatively to the ten-yearly period. I may point out that the Trevandrum series comprises only three and a half cycles, too few for any very satisfactory conclusion. It is easy, however, to inquire so what extent the Madras and Trevandrum series agree during the time we have observations from both $(1838-1876)$. Should they give the same result for these thirty-eight years, whatever that result may be, we may fairly conclude as to the probability of Trevandrum giving generally the same result as Madras.

An examination of the yearly rainfalls at the two stations during this period shows in a very marked way a cycle of about five years, or a double oscillation in the decennial period; and this for seven successive oscillations. I have in consequence sought the equations of sines giving the most probable representation of the mean oscillations (single and double) for the ten and a half year period at the two stations from the thirty-eight years' observations; these are as follow, $(y)$ being the yearly rainfall in inches:-

Madras … $y=5.4 \sin \left(\theta+50^{\circ}\right)+4.6 \sin \left(2 \theta+252^{\circ}\right)$,

'Trevandrum $y=5.6 \sin \left(\theta-17^{\circ}\right)+8.4 \sin \left(2 \theta+259^{\circ}\right)$.

While the series aie too short for any certain conchusions yet the general agreement of the equations for the two places is quite distinct.

What I desire especially to point out is the large donble oscillation in the ten and a half year cycie; at Trevandrum (where there are two monsoons) the mean range amounts to 16.3 inches; it is only $9^{\circ} 2$ inches at Madias; but the epochs of maximum and minimum are very neariy the same at both stations as shown by the angles $252^{\circ}$ and $259^{\circ}$. Also these angles give the epochs of minimum rainfall both in the years of minimuin and of maximum strii-spots.

It is not my intention to seels an explanation of this result, especially (though well shown seven times in succession) since it requires more extensive investigation, like that for ter and a half years, before any considerable weight can be given to it; I have thought it desirable, however, to bring this oscillation to the notice of investigators. The object of men of science is not to prove or disprove a case but to ascertain the truth. We are only groping at present in the darkness, yet it is not merely possible but probable that results of great practical importance may be derived from a conjoint study of terres. trial and solar physics, though they may not be the precise results which were expected or, it may be, desired. I shall endeavour at another time to give reasons for believing this.

Putting aside all that has hitherto been considered glorious to a nation in advancing science for its own sake; if we remember the vast human suffering that may be alleviated hereafter by encouraging now the study of solar actions as observed on the sun's surface, and as felt on our globe by the trembling magnet, the heaving air, and, it may be, the falling rain, there will I think be few, who know a tithe of what science has already done for humanity, who will not join in the demand for the small sum required from the nation's resources for so great an end.

JOHN ALLAN BROUN

The preceding equations cannot be compared with those for Madras and Eombay (NATUiR term for the single oscillation does not agree with that found previously from the longer series at Madras.

\section{NOTES}

The Lavoisier medal of the French Society for the Encouragement of Industry has been awarded for the present year to Mr. Walter Weldon, for the great progress realized by his manufacture of blexching powder. This medal is seldom awarded-among the few recipients being Henri St. Ciaire Dsville, Henri Giffard, Boussingault, Ferdinand de Lesseps, and Sir Charles Wheatstone. The presentation was made by M. Dumas, who delivared an eloquent address.

At the next session of the French Association for the $\Lambda \mathrm{d}$ vancement of Science, the committec appoinicd on meteorology will propose to memorialize the Cabinet to create a Meteor. ological Institute, in which will be centralized all the meteor. ological institutions of France, thus severing the connection between them and the Paris Observatory.

Thy number of stations of the French Agricuitural Meteorological Service was 1,149 on July I. All the departments except five, the poorest and the least educated, are possessed of stations. The service was inaugurated last August. Not more than 3,620 French communes are said to have telerraphic stations, so that the third part of the communes in a position to enjoy daily telegrams have availed themselves of the opportunity in less than one year. The French Agricultural and Marine Meteorological Service has a very limited credit, not more than 30,000 francs.

IN the royal castle at Niimberg the well-knum Irimalayan traveller Hermann v. Schlagintweit-Sakituliinski is exhibiting the large collection made by himself and his two brohers Adolf and Robert during their travels in India and High $A$ ita.

The proposal to found a popular Astronomical Institute at Hamburg, advocated by the optician. Dr. Hugo 5 hiocler, has been received with general favour. Indeed the project las so far exceeded the original proposal as to include a zoc l gica! garden, an aquarium, and, in fact, a great institute for the spread of scientific knowledge. Popular lectures will be given at the institute, which will be furnished with a refractor cuiting 188,000 marks, adazen of the best mirruscopes, a model of the world, planetaria, \&c. The first cost is estimated at 600,000 rarks.

A PROPOSITIOn has been made by infuntial members of the Municipal Council of Paris to establish a regular course of lec. tures on astionomy at the Montsouris Observatory. There has been no public lectureships on astronomy at Paris since Arago died, except at the Surbonne and Collége de France, but none of these lectures are for beginners.

Two living specimens of the Colorado beetle were found in Liverpool docks last week; one was taken on Wednes Jay on boaro the Spanish S.S. Carolina, which arrived about a week previously from New York, bringing sixty head of large cattle from Texas; and it was supposed to have come in the fodder for the cattle, which consisted of hay and maize. This was stored on deck above the aiter hatchway close to the saloon, and the beetle was taken crawling up the wall inside the saloon near the ceiling. The weather having been warm the windows had been open, and it could easily find admittance from the adjoining fudder, which was all but exhausted. Some delay took place in getting the ship into dock, and the cattle disembarked in consequence of a misunderstanding as to the regulations regarding the importation of cattle, so that about a week elapsed before the ship got into dock; and by the time she did get in fresh fodder had immediately to be got to supply the cattle. This relieves any anxiety which might otherwise have been felt as to other specimens having been distributed on shore with any surplus fodder. The history of the other specimen was not so clearly traced. It was said to have fallen from a stemer on to 